\title{
PENGARUH BUDAYA ORGANISASI DAN KEPUASAN KERJA KEPALA SEKOLAH TERHADAP PRODUKTIVITAS KEPALA SEKOLAH MENENGAH ATAS NEGERI DI PROVINSI DKI JAKARTA
}

\author{
DEDE HAMDANI* \\ SITI NURJANAH**
}

\begin{abstract}
This study aims to determine the influence of organizational culture and job satisfaction with work productivity state secondary school principals in the province of Jakarta. This study used survey method with path analysis technique (Path Analysis). The data collection process is done by using a questionnaire as a research instrument in this study Head of State High School In Jakarta selected as the unit of analysis with a sample size of 115 people is determined by simple random techniques (simple random sampling). The results show: First, There is influence between organizational culture with job satisfaction; Second, There is the influence of the culture of the organization with the principal productivity. Thirdly, There is the influence of job satisfaction on work productivity.
\end{abstract}

Keywords: organizational culture, job satisfaction, productivity

\section{PENDAHULUAN}

Kualitas pendidikan di Indonesia saat ini sangat memprihatinkan. Ini dibuktikan dengan indeks pembangunan manusia (IPM) Indonesia sangat rendah. Menurut United Nations Development Program, IPM

\footnotetext{
* Dede Hamdani. Alumni Fakultas Ekonomi Universitas Negeri Jakarta

** Siti Nurjanah. Dosen Fakultas Ekonomi Universitas Negeri Jakarta
}

Indonesia tahun 2011 di urutan 124 dari 187 negara yang disurvei dengan skor 0,617 peringkat ini turun dari peringkat 108 pada tahun 2010 di kawasan ASEAN Indonesia hanya unggul dari Vietnam yang memiliki nilai IPM 0,593 Laos dengan nilai IPM 0,524 Kamboja dengan nilai IPM 0,523 dan Myanmar dengan nilai IPM 0,483 Di ASEAN peringkat pertama dalam hal kualitas manusia adalah Singapura 
dengan nilai 0,866 kemudian disusul Brunei dengan nilai IPM 0,838 disusul Malaysia 0,761 Thailand 0,682 dan Filipina 0,644 salah satu komponen yang dihitung dalam penghitungan IPM adalah rata-rata lamanya sekolah. Rendahnya IPM Indonesia ini menunjukkan dampak dari alokasi $20 \%$ APBN untuk pendidikan ini belum terasa (kompas.com).

Kualitas

pendidikan

Indonesia yang rendah itu juga ditunjukkan data balitbang (2003) bahwa dari 146.052 SD di Indonesia ternyata hanya 8 sekolah saja yang mendapat pengakuan dunia dalam kategori the primary years program (PYP) dari 20.918 SMP di Indonesia ternyata hanya 8 sekolah yang mendapatkan pengakuan dunia dalam kategori the middle years program (MYP) dan dari 8.036 SMA ternyata hanya 7 sekolah saja yang mendapatkan pengakuan dunia dalam kategori the diploma program (TDP) (kampus215. blogspot.com).

Penyebab rendahnya mutu pendidikan di Indonesia tentu tidak lepas dari peran kepala sekolah dan kepemimpinan seorang kepala sekolah sebagai top leadernya. Melihat pentingnya fungsi kepemimpinan kepala sekolah, maka usaha untuk meningkatkan kinerja yang lebih tinggi bukanlah pekerjaan mudah bagi kepala sekolah karena kegiatan berlangsung dalam sebuah proses panjang yang direncanakan dan diprogram secara baik pula. Namun pada kenyataannya tidak sedikit kepala sekolah yang hanya berperan sebagai pimpinan formalitas dalam sebuah sistem alias hanya sekedar sebagai pemegang jabatan struktural sambil menunggu masa purna tugas.

Salah satu indikator keberhasilan kepemimpinan seorang kepala sekolah diukur dari mutu pendidikan yang ada di sekolah yang dipimpinnya. Dalam konteks pendidikan pengertian mutu mencakup input, proses dan output pendidikan. Input pendidikan adalah segala sesuatu yang harus tersedia karena dibutuhkan untuk berlangsungnya proses. Proses pendidikan merupakan berubahnya sesuatu menjadi sesuatu yang lain dengan mengintegrasikan input sekolah sehingga mampu mendorong motivasi, minat belajar dan benar-benar mampu memperdayakan peserta didik. Output pendidikan adalah merupakan kinerja sekolah yang dapat diukur dari kualitas, efektivitas, produktivitas, efisiensi, 
inovasi dan moral kerja. Untuk menjamin efektivitas pencapaian tujuan pendidikan hendaklah memperhatikan komponenkomponen: tenaga kependidikan, peserta didik, sistem belajar dan mengajar, fasilitas pendidikan, sistem evaluasi, waktu dan pengelolaan (Soedijarto), memantapkan kinerja sistem pendidikan nasional dalam menyiapkan manusia Indonesia memasuki abad ke 21.

\section{KAJIAN TEORI}

\section{Produktivitas}

Produktivitas bukan sematamata ditunjukkan untuk mendapatkan hasil kerja sebanyakbanyaknya, melainkan kualitas kinerja juga penting untuk di perhatikan. A Dale Timpe (2002:107) menguraikan tentang produktivitas, "productivity is a measure that compares input to output it tells you how efficient a system is performing". Produktivitas didefinisikan sebagai output barang atau jasa dari proses input sumber daya yang digunakan dalam proses produksi.Menurut Mosley, dikemukakan bahwa :

Productivity is a measure that compares ouputs to inputs. It tells you how efficiently a system is performing. Basicly, there are three ways to accomplish the 15 percent productivity increase; 1 .Increase the total output without changing the total cost, 2. Decrease the total inputs costs without changing the total output, 3.Increase the output and decrease the input costs. (Donal c. Mosley, Leon C Megginson, Paul. $\mathrm{H}$. Pietri, 2005:411-413)

Produkivitas adalah sebuah ukuran yang membandingkan output dengan input. $\mathrm{Hal}$ ini memberitahukan kepada anda seberapa efektivitasnya sebuah system dalam penerapananya. Pada dasarnya, ada tiga cara untuk melengkapi $15 \%$ peningkatan produktivitas: 1. Meningkatkan totoal output tanpa mengubah total biaya, 2. Menguraikan biaya-biaya total input tanpa mengubah total output, 3. Meningkatakan output dan mengurangi biaya-biaya input.

Koontz dan Weincrih (1988:8), "productivity is the efficiency and efficieny inputs are transformed into outputs organization". Produktivitas menyatakan efektivitas dan efisiensi dalam unjuk kerja suatu organisasi. Harsey dan Blanchard (1993:140), "productivity related with efectivity (goal) and efficiency (costand human resources that influence life). Bahwa produktivitas berhubungan dengan efektivitas 
(pencapaian tujuan) dan efisiensi (biaya dan sumberdaya manusia yang mempengaruhi kualitas hidup)

John R. Schermerhorn (2011:465), "productivity is the efficiency with inputs are transformed into outputs". Produktivitas adalah efisiensi dalam proses merubah input menjadi output.

Samuel C. Certo (2013:32) mendefinisikan produktivitas sebagai berikut, "productivity is the amount of results (output) an organization gets for a given". Produktivitas adalah jumlah hasil dari sebuah organisasi yang dapat diberikan.

John M. Ivancevich and Robert Konopaske (2013:36) mendefinisikan produktivitas sebagai berikut, "productivity is defined as output of goods and services per unit of input of resources used in a production process". Menurut John M. Ivancevich Produktivitas didefinisikan sebagai output barang atau jasa dari proses input sumber daya yang digunakan dalam proses produksi.

Menurut Mosley (2005:411), "productivity is a measure that compares input to output it tells you how efficient a system is performing". Tidak jauh berbeda dengan para ahli lainnya Mosley mendefinisikan produktivitas adalah ukuran yang membandingkan input ke output untuk memberitahukan seberapa efisien suatu sistem melakukan proses produksi.

Stephen P. Robbins and Mary Coulter (2012:520) mengatakan bahwa, "productivity is the amount of goods or service produced divided by the inputs needed to generate that output. Organizations and individual work units want to be productive". Mary Coulter menjelaskan produktivitas adalah jumlah barang atau jasa yang dihasilkan dibagi dengan input yang dibutuhkan untuk menghasilkan output tersebut. Organisasi dan unit kerja individu ingin menjadi produktif.

Stephen P. Robbins and Timothy A. Judge (2013:62) menjelaskan, "an organization is productive if it achieves its goals by transforming inputs to outputs at the lowest cost. This productivity implies both effectiveness and efficiency". Menurut Stephen P. Robbins mengatakan sebuah organisasi yang produktif jika dia dapat mencapai tujuannya dengan mengubah masukan menjadi keluaran dengan biaya terendah. 
Produktivitas menyiratkan efektifitas dan efisiensi.

Anggelo Kinicki and Brian

Williams (2011:

508-509) mendefinisikan produktivitas, "productivity is defined by the formula output divided by input for a certain period. Ouputs are all goods and services produced. Input is not solid but also capital, materials and energy produced'. Kinicki mengatakan produktivitas didefinisikan oleh rumus output dibagi dengan input untuk jangka waktu tertentu. Ouputs adalah semua barang atau jasa yang dihasilkan sedangkan input adalah modal atau bahan energi yang di gunakan dalam proses produksi.

Arouf

(Sedarmayanti, 2009:198), "productivity is the ratio between the effectiveness of producing output and efficiency of resource inputs". Hal ini berarti produktivitas adalah rasio antara efektivitas menghasilkan keluaran dan efisiensi penggunaan sumber masukan.

Muchdarsyah Sinungan didalam bukunya yang berjudul produktivitas apa dan bagaimana, dikemukakan pengertian produktivitas berdasarkan Konferensi Oslo 1984 sebagai berikut:
Productivity is a universal concept at providing more and more of goods and services for more and more people with less consumption of real resources. Relive upon and development of plants, and applications of productive practical to utilize resources efficiently, while maintaining high quality. Involves integrated application of human efforts and skill, capital, technology management, information, energy, and oher resource to bring about sustained improvements and betterment of the standards of living for all, thought a total productivity concept. (Muchdarsyah Sinungan, 2009:17)

Artinya produktivitas merupakan sebuah konsep yang umum bertujuan untuk menyediakan lebih banyak barang dan jasa kepada lebih banyak orang dengan menggunakan sumbersumber rill yang makin sedikit. Berdasarkan pada pendekatan interdisiplin untuk keefektifan tujuan, pengembangan perencanaan dan aplikasi produksi dengan menggunakan sumbersumber seefisien mungkin namun tetap memperhatikan kualitas kerja yang tinggi. Hal tersebut melibatkan usaha manusia, keterampilan, uang, teknologi, pengetahuan, tenaga dan 
sumber lainnya secara keseluruhaan untuk kemajuan standar kehidupan yang lebih baik bagi masyarakat melalui konsep produktivitas secara

\section{Budaya Organisasi}

Budaya berkaitan erat dengan persepsi terhadap nilai dan lingkungannya yang melahirkan makna dan pandangan hidup yang akan mempengaruhi sikap dan tingkah laku. Menurut Edgar $\mathrm{H}$. Schein (Fred Luthans, 2011:71) mendefinisikan budaya organisasi sebagai berikut:

A pattern of basic assumptions invented, discovered developed by a given group as it learn to cope with its problems of external adaptation and internal integration that has worked well enough to be considered valuableand therefore to be taught to new members as the correct way to perceive, think and feel in relation to those problems.

Edgar H. Schein menjelaskan sebuah pola asumsi dasar ditemukan dan dikembangkan oleh kelompok tertentu seperti belajar mengatasi masalah-masalahnya adaptasi eksternal dan integrasi internal yang telah bekerja cukup baik untuk dianggap berharga dan karena itu harus diajarkan kepada anggota baru sebagai cara yang benar untuk melihat, berpikir dan merasa dalam kaitannya dengan masalah.

John R. Schermerhorn (2011:34) mengatakan bahwa budaya organisasi, "organizational behavior whichis deveted to the study of individuals and groups in organizations". Dapat diartikan perilaku organisasi adalah ilmu khusus untuk mempelajari individu dan kelompok dalam organisasi.

Joanne Martin (Fred Luthans, 2011:34) mendefinisikan budaya organisasi Menekankan perspektif yang berbeda budaya dalam organisasi. Dia mencatat:

As individual come into contact with organizations, they come into contact with dress norms, stories people tell what goes on, the organization's formal rules and procedures, its formal codes of behavior, rituals, task, pay system, jargon, and jokes only understood by insiders, and soon. These elements are some of the manifestations of organizational culture.

Sebagai individu bersentuhan dengan organisasi, mereka datang ke dalam kontak dengan normanorma berpakaian, cerita orangorang yang menceritakan apa yang 
terjadi, aturan formal organisasi dan prosedur, kode formal perilaku, ritual, tugas, sistem gaji, jargon dan lelucon hanya dipahami oleh orang dalam dan segera. Unsur-unsur adalah beberapa manifestasi budaya organisasi. Namun menambahkan bahwa ada perspektif lain dari budaya.

Menurut Edgar $\mathrm{H}$. Schein yang dikutip oleh Angelo Kinicki and Brian Williams (2011:236), "organizational culture, sometimes called corporate culture, is a system of shared beliefs and values that develops within and organization and guides the behavior of its members". Budaya organisasi atau sering disebut budaya perusahaan adalah sistem kepercayaan dan nilai-nilai bersama yang berkembang dalam organisasi dan menjadi panduan perilaku anggotanya.

Angelo Kinicki and Brian Williams (2011:236), mendefinisikan budaya organisasi sebagai berikut, "culture is transmitted to employees in several ways, most often throught such devices as symbols, stories, heroes, rites and rituals". Budaya disebarkan kepada karyawan dalam beberapa cara yang paling sering melalui perangkat seperti simbol, cerita, pahlawan, upacara dan ritual.

A. William P. Dobson and M. Walter (2010:416) mendefiniskan: Organizational culture consists of the values and assumptions shared within an organization. It defines what is important and unimportant in the company and consequently, directs everyone in the organization toward the right way of doing things.

Budaya organisasi terdiri dari nilai-nilai dan asumsi bersama dalam sebuah organisasi. Mendefinisikan apa yang penting dan tidak penting dalam perusahaan dan akibatnya mengarahkan semua orang di organisasi terhadap cara yang benar dalam melakukan sesuatu.

Menurut Edgar $H$. Schein didalam bukunya John R. Schermerhorn (2011:260), "organizational culture this is the system of shared belief and values that shapes and guides the behavior of its members". Budaya organisasi adalah sistem kepercayaan dan nilai-nilai bersama yang terbentuk dan dijadikan panduan perilaku anggotanya.

Stephen P. Robbins and Mary Coulter (2011:83) mendefinisikan budaya organisasi, "how employees 
learn culture, employees learn an organizations' culture in a number of ways. The most common are stories, rituals, material symbols and language". Bagaimana karyawan mempelajari suatu budaya organisasi dalam beberapa cara. Yang paling umum adalah cerita, ritual, simbol materi dan bahasa.

Livari Juhani and Magda Huisman didalam bukunya James L. Gibson (2012:31) mengatakan, "definitions of culture describe it as: symbol, language, ideologies, rituals and myths". Definisi budaya menggambarkannya sebagai: simbol, bahasa, ideologi, ritual dan mitos.

Jason A. Colquitt (2013:518) organisasi budaya adalah, "organizational culture as the shared social knowledge within an organization regarding the rules, norms and values that shape the attitudes and behavior of it employess". Budaya organisasi sebagai pengetahuan sosial bersama dalam sebuah organisasi mengenai aturan, norma-norma, nilai-nilai yang membentuk sikap dan perilaku.

Menurut Jason A. Colquitt (2013:519), "culture components, there are three major components to an organizational culture: observable artifacts, espoused values and basic underlying assumptions". Komponen budaya, ada tiga komponen utama budaya organisasi: artefak diamati, nilainilai yang dianut dan asumsi-asumsi yang mendasari dasar.

Edgar $\mathrm{H}$ Scehin yang dikutip

oleh Angelo Kinicki dan Brian Williams (2011:243-245) mengatakan ada 11 cara menanamkan budaya didalam organisasi :

Eleven ways cultures becomes embedded in organizations; 1 1) formal statements, 2) slogan dan sayings, 3) stories, legends \& myths 4) leaders reactions to crises, 5) role modeling, training \& coaching, 6) physical design 7) reward, titles, promotions and bonuses, 8) organizational goals \& performance criteria,

9) measurable \& controllable activities 10) organizational structure 11) organizational system and procedures.

Ada sebelas cara budaya menjadi tertanam dalam organisasi; 1) pernyataan formal, 2) slogan dan perkataan, 3) cerita, legenda, \& mitos, 4) pemimpin reaksi terhadap krisis, 5) peran pemodelan, training \& pembinaan, 6) desain fisik, 7) 
reward, judul, promosi, bonus, 8) organisasi tujuan \& kriteria kinerja, 9) terukur \& terkendali kegiatan, 10) struktur organisasi, 11) organisasi sistem dan prosedur.

Menurut John M. Ivancevich (2011:44) mendefinisikan budaya organisasi, "organization culture refres to a system of shared meaning held by member that distinguishes the organization from other organizations. culture can have an impact on the behavior, productivity and expectations of employes". Dapat dijelaskan bahwa organisasi budaya adalah sistem makna kebersamaan yang diselenggarakan oleh anggota suatu organisasi yang dapat membedakan antara organisasi satu dengan organisasi yang lainnya.

\section{Kepuasaan Kerja}

Kepuasan kerja merupakan salah satu faktor yang harus diperhatikan dalam upaya meningkatkan produktivitas pegawai. Menurut John R. Schermerhorn (2011:347) mendefinisikan kepuasan kerja, "job satisfaction is the degree to which an individual feels positive or negative about a job". Kepuasan kerja adalah sejauh mana seseorang merasa positif atau negatif tentang pekerjaan.

Jason A. Colquiit (2013:96) mengatakan, "job satisfaction is defined as apleasurable emotional state resulting form the appraisal of one's job on job experiences. In the word, it represent how you feel about your job and what you think about job". Kepuasaan kerja didefinisikan sebagai emosi atau perasaan menyenangkan atau tidak terhadap hasil penilaian suatu pekerjaan dan pengalaman kerja. Dan dapat menggambarkan bagaimana perasaan anda tetang pekerjaan dan apa yang anda pikir tentang pekerjaan itu.

Menurut Robert Kreitner and Angelo Kinicki (2010:170), "job satisfaction is an affective or emotional response toward various facets of one's job". kepuasan kerja merupakan respon afektif atau emosional terhadap berbagai aspek pekerjaan seseorang.

E. A Locke didalam bukunya Steven L. Mc Shane and Mary Ann Von Glinov (2010:108) mengatakan bahwa, "job satisfaction a person evaluation of his her job and work context, is probably the most studied attitude in organizational behavior". Kepuasan kerja seseorang adalah evaluasi diri dari 
pekerjaannya dan konteks kerja, mungkin sikap yang paling banyak dirasakan dalam budaya organisasi.

James L. Gibson, (2012:104) "job satisfaction is an attitude that individuals have about their jobs. It results form their perception of their jobs, based on factors of the work environment work group affiliation, working condicitons and fringe benefit". Kepuasaan kerja adalah sikap seseorang tentang pekerjannya. Hal ini sebagai hasil persepsi tentang pekerjaannya yang didasari oleh faktor lingkungan kerja, keamanan kerja, kondisi kerja dan pendapatannya.

Menurut Angelo Kinicki dan Brian K. Williams (2011:350) mengatakan bahwa kepuasan kerja adalah.

Job satisfaction is the extent to which you feel positive or negative about various aspects of your work. Their overall satisfaction depends on how they feel about several components, such as work, pay, promotions, coworkers and supervision.

Kepuasan kerja adalah sejauh mana merasa positif atau negatif tentang berbagai aspek dari pekerjaannya. Kepuasan mereka secara keseluruhan tergantung pada bagaimana perasaan mereka tentang beberapa komponen, seperti pekerjaan itu sendiri, gaji, promosi, rekan kerja dan pengawasan.

Hal yang senada di sampaikan oleh $\mathrm{E}$. A Locke tentang kepuasan kerja:

Locker gives a comprehensive definition of job satisfaction as involving cognitive, affective, and evaluative reactions or attitudes and states it is a pleasurable or positive emotional state resulting from the appraisal of one's job or job experience. Job satisfaction is a result of employees perception of how well their job provides those things that are viewed as important. (Fred Luthans, 2011:141)

Locker memberikan definisi yang komprehensif dari kepuasan kerja dan melibatkan kognitif afektif reaksi, evaluatif atau sikap dan menyatakan itu adalah keadaan emosi menyenangkan atau positif yang dihasilkan dari penilaian pekerjaan atau pengalaman kerja. Kepuasan kerja adalah hasil dari persepsi karyawan dari seberapa baik pekerjaan mereka memberikan hal-hal yang dianggap penting.

John R. Schermerhorn (2011:348) mendefisinikan kepuasan kerja, "the following are among the job satisfaction facets 
most commonly measured: work itself, quality of supervision, cowokers, opportunities, pay, work conditions and security'. berikut ini adalah salah satu aspek kepuasan kerja yang paling sering diukur: pekerjaan itu sendiri, kualitas pengawasan, rekan kerja, peluang, gaji, kondisi kerja dan keamanan.

\section{Hipotesis Penelitian}

Berdasarkan teori di atas, maka hipotesis yang dapat di ajukan sebagai berikut: "Terdapat hubungan yang positif antara budaya organisasi dan kepuasan kerja kepala sekolah sma negeri di provinsi DKI Jakarta terhadap produktivitas kerjanya. Semakin kondusif budaya organisasi dan kepuasaan kerja maka semakin tinggi produktivitas dan sebaliknya semakin tidak kondusif budaya organisasi dan kepuasan kerja maka semakin rendah produktivitasnya

\section{Metode Penelitian}

Penelitian ini menggunakan metode survey dengan teknik analisis jalur (path analysis). Proses pengumpulan data dilakukan dengan menggunakan angket sebagai instrument penelitian. Penelitian ini menganalisis pengaruh satu variabel terhadap variabel lain.
Dalam hal ini variabel yang dikaji ada dua macam yaitu: (1) variabel eksponen dan (2) variabel endogen. Variabel eksponen yaitu budaya organisasi $\left(\mathrm{X}_{1}\right)$ dan kepuasaan kerja $\left(X_{2}\right)$ disini berpengaruh langsung dan secara tidak langsung terhadap variabel endogen yaitu produktivitas $\left(X_{3}\right)$.

\section{Hasil Penelitian dan pembahasan}

a. Uji Signifikansi dan Linieritas Koefisien Regresi Produktivitas atas Budaya Organisasi

Dari data hasil perhitungan untuk penyusunan model persamaan regresi antara produktivitas dengan budaya organisasi pada lampiran 6 diperoleh konstanta regresi $\mathrm{a}=$ 71,45 dan koefisien regresi $b=$ 0,53 . Dengan demikian hubungan model persamaan regresi sederhana adalah $\hat{\mathrm{X}}_{3}=71,45+$ $0,53 X_{1}$. Sebelum model persamaan regresi tersebut dianalisis lebih lanjut dan digunakan dalam menarik kesimpulan, terlebih dahulu dilakukan uji signifikansi dan linieritas persamaan regresi. Hasil perhitungan uji signifikansi dan linieritas disusun pada tabel ANAVA seperti pada tabel 4.8 . 
Tabel 4.8 ANAVA Untuk Uji Signifikansi dan Linieritas Koefisien Regresi $\hat{\mathbf{X}}_{3}=$ $71,45+0,53 X_{1}$

\begin{tabular}{|l|c|c|c|c|c|c|}
\hline \multicolumn{1}{|c|}{ Sumber } & $\mathrm{dk}$ & $\begin{array}{c}\text { Jumlah } \\
\text { Kuadrat (JK) }\end{array}$ & $\begin{array}{c}\text { Rata-rata Jumlah } \\
\text { Kuadrat (RJK) }\end{array}$ & $\mathrm{F}_{\text {hitung }}$ & \multicolumn{2}{|c|}{$\mathrm{F}_{\text {tabel }}$} \\
\cline { 1 - 3 } & & $\mathrm{a}=0,05$ & $\mathrm{a}=0,01$ \\
\hline Total & 89 & 1345919 & & & & \\
Regresi a & 1 & 1337639,56 & & & & \\
Regresi b/a & 1 & 3180,63 & 3180,63 & $54,27 * *$ & 3,95 & 6,94 \\
Residu & 87 & 5098,81 & 58,61 & & & \\
\hline Tuna Cocok & 31 & 2242,65 & 72,34 & $1,42^{\mathrm{ns}}$ & 1,67 & 2,06 \\
Galat & 56 & 2856,16 & 51,00 & & & \\
\hline
\end{tabular}

Keterangan :

** : Regresi sangat signifikan $(54,27>6,94)$

ns : Regresi berbentuk linier $(1,42<1,67)$

$\mathrm{dk} \quad$ : Derajat kebebasan

JK : Jumlah kuadrat

RJK : Rata-rata jumlah kuadrat

Persamaan regresi $\mathrm{X}_{3}=$ $71,45+0,53 X_{1}$, untuk uji signifikansi diperoleh Fhitung $=54,27$ lebih besar dari pada Ftabel 3,95 pada $a=0,01$. Karena Fhitung > Ftabel maka persamaan regresi dinyatakan sangat signifikan. Untuk uji linieritas diperoleh Fhitung = 1,42 lebih kecil dari pada Ftabel $=1,67$ pada $\mathrm{a}=0,05$. Karena Fhitung < Ftabel maka sebaran titik yang terestimasi membentu garis linier dapat diterima. Secara visual dapat dilihat pada gambar 4.4 .

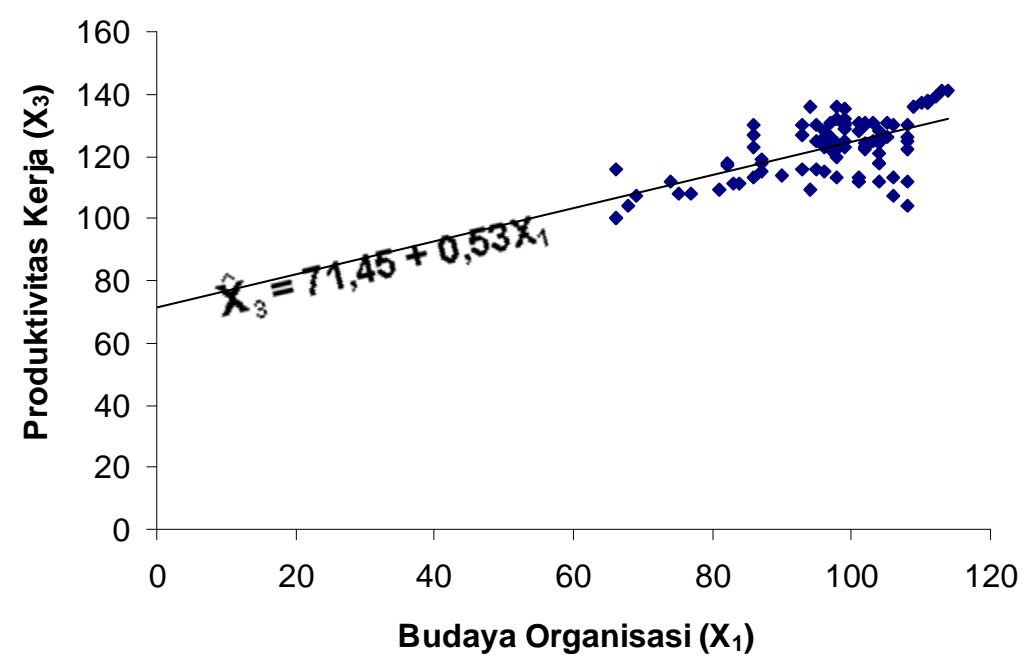


Gambar 4.4 Grafik Persamaan Regresi $\hat{\mathbf{X}}_{3}=71,45+0,53 \mathbf{X}_{1}$

b. Uji Signifikansi dan Linieritas Koefisien Regresi Produktivitas atas Kepuasan Kerja

Dari data hasil perhitungan untuk penyusunan model persamaan regresi antara produktivitas dengan kepuasan kerja pada lampiran 6 , diperoleh konstanta regresi $a=80,85$ dan koefisien regresi $b=0,39$. Dengan demikian hubungan model persamaan regresi sederhana adalah $\hat{\mathrm{X}}_{3}$ $=80,85+0,39 \times 2$. Sebelum model persamaan tersebut dianalisis lebih lanjut untuk digunakan dalam menarik kesimpulan, terlebih dahulu dilakukan uji signifikansi dan linieritas persamaan regresi. Hasil perhitungan uji signifikansi dan linieritas disusun pada tabel ANAVA seperti terlihat pada tabel 4.9.

Tabel 4.9 ANAVA Untuk Uji Signifikansi dan Linieritas Koefisien Regresi $\hat{\mathbf{X}}_{3}=80,85+0,39 \times 2$

\begin{tabular}{|l|c|c|c|c|c|c|}
\hline \multirow{2}{*}{ Sumber } & \multirow{2}{*}{$\mathbf{d k}$} & $\begin{array}{c}\text { Jumlah } \\
\text { Kuadrat (JK) }\end{array}$ & $\begin{array}{c}\text { Rata-rata } \\
\text { Jumlah Kuadrat } \\
\text { (RJK) }\end{array}$ & $\mathbf{F}_{\text {hitung }}$ & \multicolumn{2}{|c|}{$\mathbf{F}_{\text {tabel }}$} \\
\cline { 1 - 3 } & & $\mathbf{a}=\mathbf{0 , 0 5} \mathbf{a}=\mathbf{0 , 0 1}$ \\
\hline Total & 89 & 1345919 & & & & \\
\hline Regresi a & 1 & 1337639,56 & & & & \\
Regresi b/a & 1 & 2621,36 & 2621,36 & $40,31 * *$ & 3,95 & 6,94 \\
Residu & 87 & 5658,08 & 65,04 & & & \\
\hline Tuna Cocok & 45 & 3082,86 & 68,51 & $1,12^{\text {ns }}$ & 1,66 & 2,05 \\
Galat & 42 & 2575,22 & 61,31 & & & \\
\hline
\end{tabular}

Keterangan :

$\begin{array}{ll}* * & \text { : Regresi sangat signifikan }(40,31>3,95 \mathrm{I}) \\ \mathrm{ns} & \text { : Regresi berbentuk linier }(1,12<1,66) \\ \mathrm{dk} & \text { : Derajat kebebasan } \\ \mathrm{JK} & \text { : Jumlah kuadrat } \\ \mathrm{RJK} & \text { : Rata-rata jumlah kuadrat }\end{array}$

Persamaan regresi $\mathrm{X}_{3}=$ $80,85+0,39 X_{2}$, untuk uji signifikansi diperoleh Fhitung $=40,31$ lebih besar dari Ftabel
6,94 pada $a=0,01$. Karena Fhitung > Ftabel maka persamaan regresi dinyatakan sangat signifikan. Untuk uji 
linieritas diperoleh Fhitung sebesar 1,12 lebih kecil dari Ftabel 1,66 pada $a=0,05$. Karena Fhitung < Ftabel maka sebaran titik yang terestimasi membentuk garis linier dapat diterima. Secara visual dapat dilihat pada gambar 4.5.

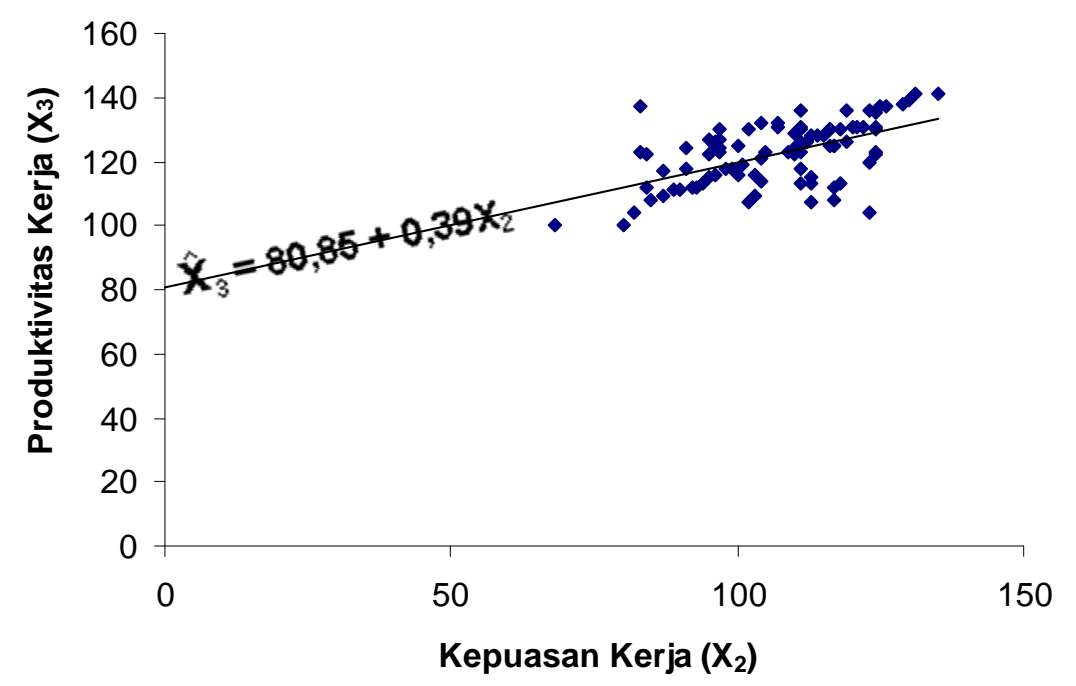

Gambar 4.5 Grafik Persamaan Regresi $\hat{\mathbf{X}}_{3}=80,85+0,39 \mathrm{X}_{2}$

c. Uji Signifikansi dan Linieritas Koefisien Regresi Kepuasan Kerja atas Budaya Organisasi

Dari data hasil perhitungan untuk penyusunan model persamaan regresi antara kepuasan kerja dengan budaya organisasi pada lampiran 6 diperoleh konstanta regresi $\mathrm{a}=$ 38,48 dan koefisien regresi $b=$ 0,71 . Dengan demikian hubungan model persamaan

Tabel 4.10 ANAVA Untuk Uji Signifikansi dan Linieritas Koefisien

$$
\text { Regresi } \hat{\mathbf{X}}_{2}=38,48+0,71 \mathrm{X}_{1}
$$


Dede Hamdani \&: Pengaruh Budaya Organisasi dan Kepuasan Kerja Kepala Sekolah Terhadap Produktivitas

\begin{tabular}{|c|c|c|c|c|c|c|}
\hline \multirow{2}{*}{ Sumber } & \multirow{2}{*}{$\mathrm{dk}$} & \multirow{2}{*}{$\begin{array}{c}\text { Jumlah } \\
\text { Kuadrat (JK) }\end{array}$} & \multirow{2}{*}{$\begin{array}{c}\text { Rata-rata Jumlah } \\
\text { Kuadrat (RJK) }\end{array}$} & \multirow{2}{*}{$F_{\text {hitung }}$} & \multicolumn{2}{|c|}{$F_{\text {tabel }}$} \\
\hline & & & & & $a=0,05$ & $a=0,01$ \\
\hline Total & 89 & 1031399 & & & & \\
\hline Regresi a & 1 & 1014258,44 & & & & \\
\hline Regresi b/a & 1 & 5666,39 & 5666,39 & $42,96 * *$ & 3,95 & 6,94 \\
\hline Residu & 87 & 11474,17 & 131,89 & & & \\
\hline Tuna Cocok & 31 & 5245,07 & 169,20 & $1,52^{\mathrm{ns}}$ & 1,67 & 2,06 \\
\hline Galat & 56 & 6229,10 & 111,23 & & & \\
\hline
\end{tabular}

Keterangan :
** : Regresi sangat signifikan $(42,96>6,94)$
ns : Regresi berbentuk linier $(1,52<1,67)$
dk : Derajat kebebasan
JK : Jumlah kuadrat
RJK : Rata-rata jumlah kuadrat

Persamaan regresi $\hat{\mathrm{X}}_{2}=38,48$ dari pada Ftabel $=1,67$ pada $\mathrm{a}=$ $+0,71 X_{1}$, untuk uji signifikansi diperoleh Fhitung $=42,96$ lebih besar dari Ftabel 6,94 pada $a=$ 0,01. Karena Fhitung > Ftabel maka persamaan regresi dinyatakan 0,05. Karena Fhitung < Ftabel maka sebaran titik yang terestimasi membentuk garis linier dapat diterima. Secara visual dapat dilihat pada gambar 4.6. sangat signifikan. Untuk uji linieritas diperoleh Fhitung $=1,52$ lebih kecil

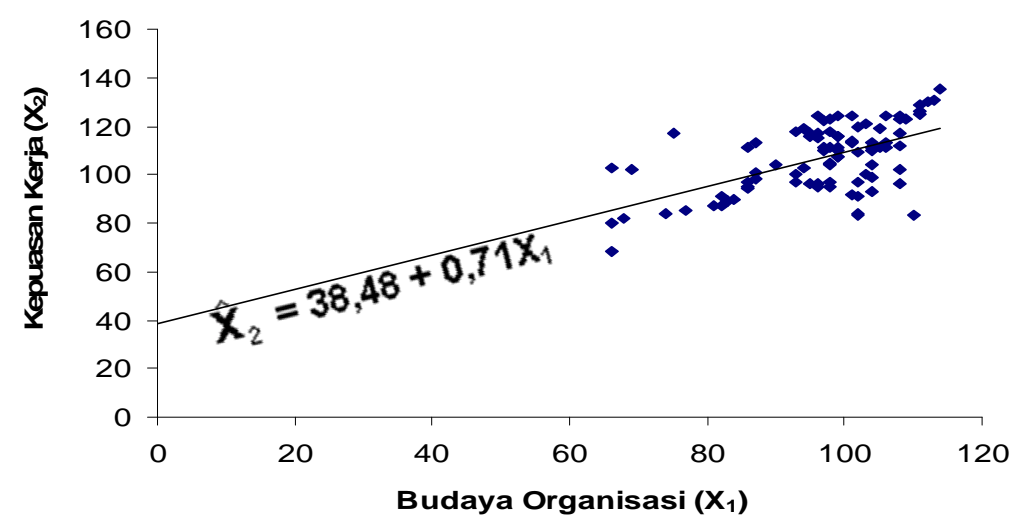

Gambar 4.6 Grafik Persamaan Regresi $\hat{\mathbf{X}}_{2}=38,48+0,71 \mathrm{X}_{1}$

Dari hasil analisis pada bagian terdahulu dan proses perhitungan yang dilakukan pada lampiran 6 , dapat dirangkum sebagai berikut: 
Tabel 4.11 Matriks Koefisien Korelasi Sederhana antar Variabel

\begin{tabular}{|c|c|c|c|c|}
\hline \multicolumn{2}{|c|}{ Matrik } & \multicolumn{3}{|c|}{ Koefisien Korelasi } \\
\cline { 3 - 5 } & $\mathrm{X}_{1}$ & $\mathrm{X}_{2}$ & $\mathrm{X}_{3}$ \\
\hline $\mathrm{X}_{1}$ & 1,00 & 0,575 & 0,620 \\
\hline $\mathrm{X}_{2}$ & $t_{\text {hitung }}$ & $6,56^{* *}$ & 1,00 & 0,563 \\
\hline $\mathrm{X}_{3}$ & $t_{\text {hitung }}$ & $7,37^{* *}$ & $6,36^{* *}$ & 1,00 \\
\hline Koefisien: & $t_{\text {tabel }}(0,05)=1,66$ & \\
& $t_{\text {tabel }}(0,01)=2,37$ & \\
\hline
\end{tabular}

Dari tabel 4.11 dapat terlihat bahwa korelasi antara budaya organisasi dengan kepuasan kerja sebesar 0,5875. Dengan nilai koefisien $t_{\text {hitung }}$ sebesar 6,56 $>t_{\text {tabel }}$ sebesar 2,37 pada $a=0,01$ sehingga dengan demikian dapat dinyatakan bahwa korelasi antara $\mathrm{X}_{1}$ dan $\mathrm{X}_{2}$ sangat signifikan.

Korelasi antara budaya organisasi dengan produktivitas sebesar 0,620. Dengan nilai koefisien $t_{\text {hitung }}$ sebesar 7,37 $>t_{\text {tabel }}$ sebesar 2,37 pada $a=0,01$ sehingga dengan demikian dapat dinyatakan bahwa korelasi antara $\mathrm{X}_{1}$ dan $\mathrm{X}_{3}$ sangat signifikan.

Korelasi antara kepuasan kerja dengan produktivitas sebesar 0,563. Dengan nilai koefisien $t_{\text {hitung }}$ sebesar $6,36>t_{\text {tabel }}$ sebesar 2,37 pada $a=$
0,01 sehingga dengan demikian dapat dinyatakan bahwa korelasi antara $\mathrm{X}_{2}$ dan $\mathrm{X}_{3}$ sangat signifikan.

Setelah nilai koefisien korelasi masing-masing variabel diperoleh, selanjutnya dapat dihitung koefisien jalur dengan cara mensubstitusikan nilai koefisien korelasi ke dalam persamaan rekursif yang telah ditentukan sebelumnya. Dengan menggunakan perhitungan matriks determinan diperoleh nilai koefisien masing-masing jalur. Selanjutnya menghitung nilai koefisien thitung pada koefisien jalur untuk mengetahui signifikansi pengaruh yang diberikan oleh masing-masing variabel eksogen terhadap variabel endogen. Ringkasan model dapat terlihat pada gambar 4.7 sebagai berikut 


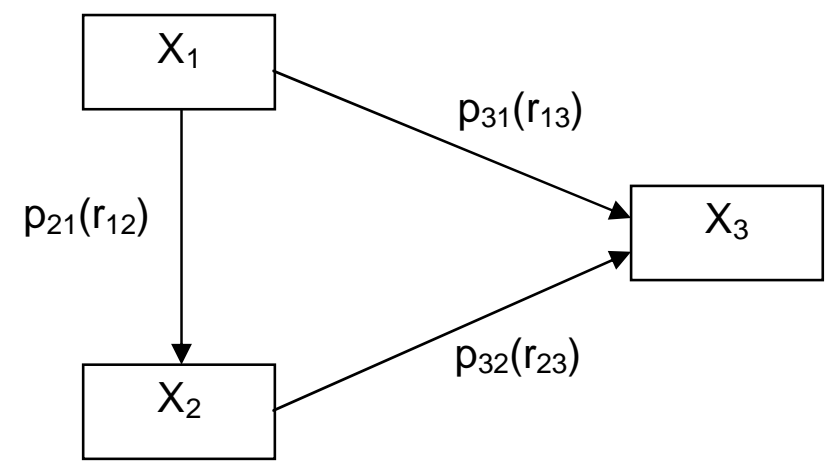

Gambar 4.7 Model Hubungan Struktural Antar Variabel

Dari diagram jalur ini diperoleh tiga koefisien jalur, yaitu $p_{31}, p_{32}$, $\mathrm{p}_{21}$ dan tiga koefisien korelasi yaitu $r_{12}, r_{13}, r_{23}$. Berdasarkan hasil perhitungan koefisien korelasi pada tabel 4.9 di atas dan menggunakan bantuan program komputer Excel, maka nilai koefisien untuk setiap jalur dihitung dan diuji signifikansinya dengan statistik uji t. Besar $C_{11}=C_{22}=1,494$. Apabila jalur yang diuji menunjukkan nilai koefisien jalur tidak signifikan maka jalur tersebut akan dihilangkan dan model hubungan struktural antar variabel dimodifikasi, serta nilai koefisien jalurnya dihitung kembali.

\section{KESIMPULAN DAN SARAN}

\section{Kesimpulan}

Penelitian ini berhasil menguji hipotesis yang diajukan, berdasarakn hasil penelitian yang telah di lakukan maaka dapat disimpulkan bahwa terdapat hubungan yang positif antara budaya organisasi dan kepuasan kerja terhadap produktivitas kerja kepala sekolah SMA Negeri di Provinsi DKI Jakarta. Dan sebaliknya semakin tidak kondusif budaya organisasi dan kepuasaan kerja maka akan berdampak negative terhadap produktivitas kerja kepala sekolah

\section{Saran}

Berdasarkan kesimpulan penelitian disarankan berbagai upaya yang dapat dilakukan dalam rangka meningkatkan produktivitas kerja kepala sekolah di Sekolah Menengah Atas Negeri di Provinsi DKI Jakarta.

1. Dinas Pendidikan Provinsi DKI Jakarta mengembangkan dan mensosialisasikan budaya organisasi sekolah yang baik seperti pelaksanaan bahasa Indonesia yang baik dan benar dalam kehiduapan di sekolah, 
penerapan norma-norma yang sesuai dengan budaya kita budaya timur yang sopan dan santun.

2. Dinas Pendidikan Provinsi DKI Jakarta memperhatikan kepuasan kerja kepala sekolah dengan memberikan kesempatan untuk mengembangkan diri kepada kepala sekolah dan dapat mewujudkan budaya organisasi yang baik di sekolah yang di pimpinnya. Dengan demikian dapat meningkatkan kepuasan kerja kepala sekolah atas apa yang sudah di kerjakan selama memimpin kepala sekolah.

3. Memberikan pengarahan kepada kepala sekolah bagaimana mengefektifkan dan mengefisiensi waktu dalam bekerja, dengan tujuan meningkatakan produktivitas kerja kepala sekolah.

\section{DAFTAR PUSTAKA}

Certo C. Samuel. 2013. Supervision Concepts and skill building. New York: Mc Graw Hill.

Colquitt A.Jason, Jeffery A. lepine and Michaell J. Wesson. 2013. Organizational Behavior: improving performance and commitment in the workplace. New York: Mc Graw Hill.

Ivancevich M. John, Robert Konopaske. 2013. Human Resource Management. New York: Mc Graw Hill.

Kinicki. Angelo. Brian K. Williams. 2011. Management a practical Introduction. New York: Mc Graw Hill.

Kreitner, Robert. Angelo Kinicki. 2010.

Organizational Behavior. New York: Mc Graw Hill.

Koontz, Harold. Heinz Weinrich, 1988. Management

(Singapore: MC Graw Hill,

Luthans, Fred. 2011. Organizational Behavior an Evidence-based approach.New York: Mc Graw Hill.

McShane L. Steven, Mary Ann Von Glinov. 2010. Organizational Behavior. New York: Mc Graw Hill.

Mosley C. Donal, Leon C. Megginson, Paul H. Pietri, 2005. Supervisory Management: The Art of Inspring, Empowering, and Developing People. US: South-Westerm: Thomson Corporation, 
Mullins, Laurie J. 2005. Management and Organizational Behavior, London Prentice Hall,

Robbins. P. Stephen. Mary Coulter. 2012. Management. New York: Pearson.

Robbins. P. Stephen. Timothy A. Judge. 2013. Organizational Behavior. New York: Pearson.

Schermerhorn, John R. 2011. Introduction to Management, USA: Wiley\& Son, inc.

Sedarmayanti, 2009. Sumber Daya Manusia dan Produktivitas Kerja, Bandung : Penerbit CV Mandar Maju,

--------------, 2009. Tata Kerja dan Produktivitas Kerja: Suatu Tinjauan Dari Aspek Ergonomi atau Kaitan Antara Manusia Dengan Lingkungan Kerjanya, Bandung: Penerbit CV.Mandar Maju,

Sinungan, Muchdarsyah. 2010.

Produktivitas apa dan bagaimana. Jakarta: PT. Bumi Aksara,

Timpe, Dale A., 2002. Produktivtas Seri Sumber Daya Manusia. Jakarta: PT. Gramedia, Wibowo, 2010. Manajemen Kinerja, Edisi Kedua, Rajawali Pers,

Entis

Sutisna,.http://enewsletterdis dik.wordpress.com/2009/07/ 10/ periodisasi -masajabatan-kepala-sekolah-danpeningkatan-mutupendidikan/ (Diakses pada 10 Oktober 2012)

http://nasional.kompas.com/read/20 12/04/17/12214022/Indeks.P embangunan.Manusia.Indone sia.Sangat.Rendah. (diakses pada tanggal 1 November 2012)

http://kampus215.blogspot.com/201 2/08/peran-kepala-sekolahdalam meningkatkan 2028.html (diakses pada 16 November 2012) 